\title{
Predictions of school mentors' effort in teacher education programmes
}

Mentoring of pre-service teachers in their school practicum is vital to integrating different parts of the educational programs and supporting the pre-service teachers to become educational professionals, but for mentors in schools this task often comes on top of the other requirements they face as teachers.

In this study, we present findings from a self-report survey completed by 295 mentors in two teacher education institutions in Norway. Using structural equation modelling of cross-sectional survey data, the study explores predictions of the effort mentors put into their work in supporting the development of preservice teachers. The findings indicate that affective commitment predicts mentor's efforts in mentoring and that professional development of mentors through programs designed to develop a professional identity as mentors could enhance their feeling of being teacher educators, and thereby having the willingness to put effort into their jobs as mentors.

Keywords: mentor effort; mentor professionalism; mentor education; affective commitment 


\section{Introduction}

This study examines mentoring efforts in teacher education. For both pre-service teachers and their mentors, it is about trying to be committed for the tasks at hand. Because pre-service teachers' practicum impacts their commitment to the teaching profession, the mentor's job becomes even more important. Mentoring pre-service teachers is a primary factor that contributes to teachers' professional development (Feiman-Nemser 2001; Hobson et al. 2009). However, it is widely reported that mentors are poorly prepared to work with pre-service teachers (Hobson et al. 2009). Mentors' lack of education and training prevents them from supporting student teachers (Clarke, Triggs, and Nielsen 2014).

Furthermore, teachers consistently face the issue of making an extra effort. School authorities require teachers in school to show results, prompting them to develop their assessment practices and undergo personalised training (Skaalvik and Skaalvik 2018). Mentors that are well-prepared for the task and willing to spend time observing, listening and talking with students significantly contribute to pre-service teachers' growth and development. For mentors of pre-service teachers, this task often piles onto additional requirements they face as teachers. There is little understanding of the additional demands placed on mentors in schools, and how those demands influence the images they hold of themselves as teacher educators of preservice teachers (Goodfellow 2000, 25; Bullough Jr. 2005). Although effort is a key term in our vocabulary about education, only a few studies have been conducted to investigate what factors are related to the level of effort teachers exert in school (Stables et al. 2014).

This study aims to identify antecedents of school mentors' effort. The findings could implicate contributions in teacher education that could lead to a change into a more professionalization of the mentor's role. We analysed data from a questionnaire 
given to 295 mentors affiliated with three teacher education programs at two universities.

In a broader sense, this study focuses on several challenges in teacher education concerning mentor professionalism. Educating teachers in different sites remains one of the most prominent challenges, and the job is seen very complex for teacher educators operating in a field of campus-based teaching on one side and school-based practice on the other. University-based teacher educators have argued that school-based mentors do not connect classroom experiences with relevant theories and research (Korthagen 2010; Korthagen and Wubbels 1995).

Teachers' mentoring responsibilities exist in addition to their normal teaching obligations, which can potentially lead to unmanageable workloads (Lee and Feng 2007; Robinson and Robinson 1999; Simpson, Hastings and Hill 2007). Constrained timeframes can contribute to a lack of persistence and professionalism in their mentoring roles. As a consequence, many teachers may not feel a strong commitment to their mentorship and thereby are not willing or able to devote extra effort to these responsibilities.

In other words, effort is a variable present in teachers' everyday lives—one that is particularly present when mentoring pre-service teachers. Being a mentor can, however, enhance teachers' self-esteem and professionalism. By training pre-service teachers, mentors become valuable contributors to the professional community of teacher educators (Bodoczky and Malderez 1997; Hobson and Malderez 2013).

Policymakers in Norway have acknowledged the importance of mentor education in professionalising mentoring practices. The overall policy and legal framework for Norway's teacher education system are established by the Norwegian government through the Ministry of Education and Research (Ministry of Education and 
Research 2013, 2016). In Norway, mentors are now required to undergo training before mentoring pre-service teachers (Ministry of Education and Research 2013, 2016). The Norwegian government's endeavour to raise the quality of pre-service mentoring through formal education is unique in both the European and international contexts (Smith and Ulvik 2014). The responsibility for mentor education in Norway usually falls upon the teacher education institution provider, although recent regulations recommend that mentors be trained via a university programme. Thus far, only some institutions have introduced compulsory programmes for mentors. Of the approximately 45,000 pre-service teacher students in Norway, many are mentored by educators without formal mentor training.

Furthermore, teacher educators' ability to theorise practices and reflect on their own teaching styles is crucial for integrating mentors into teacher education (Korthagen 2004; Orland-Barak 2016). Korthagen (2004) emphasised the importance of reflection in new teachers' professional development to prepare them for challenges in practiceoriented experiences. If mentors are better integrated into teacher education programmes, it may increase their sense of investment in the mentoring process.

\section{Previous research on predictions of school mentors' effort}

Finding relevant literature investigating factors behind mentor effort proved challenging. To our knowledge, no studies have statistically operationalised and examined the concept of effort in relation to mentoring. Examining a variety of scientific sources, Stables et al. (2014) argued that it may not be possible or even preferable to find an essentialist definition of effort. Therefore, in the section on existing research, we elaborate on research related to mentor effort in a broader perspective. Several common findings have emerged concerning factors related to the unique efforts required of school-based mentors. These relate to contextual support for mentoring, 
mentor preparation, and personal aspects related to mentoring (Aspfors and Fransson 2015).

Both teachers' and mentors' professional development should be guided by empirical evidence and relevant theories (Feiman-Nemser 2001; Hobson et al. 2009). Mentors who agree to train pre-service teachers often consider themselves teachers first and teacher educators second, which can complicate finding the optimal balance between practical and theoretical teacher education. Research shows that when mentors are involved in the design and evaluation of their programmes, mentoring is more likely to lead to positive outcomes (Evans and Abbott 1997). Coherent programmes that are not fragmented between different contributors will also produce positive outcomes in the professionalisation of pre-service teachers (Goodlad 1990; Hascher, Cocard, and Moser 2004; Hobson et al. 2008).

Mentors are meant to contribute to teachers' professional development. However, these mentors' professional development is almost non-existent in many contexts, which can lead to feelings of isolation and inadequacy (Bullough Jr. 2005; Orland-Barak 2014). The absence of proper mentor education obliges mentors to draw almost exclusively on their own experiences when guiding pre-service teachers (Hobson et al. 2009; Knowles and Cole 1996). Some studies have also suggested that mentoring is more likely to lead to positive outcomes if mentors receive some form of incentive, recognition, or financial compensation for their work (Evans and Abbott 1997; Simpson, Hastings, and Hill 2007).

Mentors who do not receive appropriate mentor training are more likely to face difficulties in their professional performance (Hobson and Malderez 2013; Kochan, Searby, George, and Edge 2015; Lejonberg, Elstad, and Christophersen 2015; Thornton 2014). Ulvik and Sunde (2013) argued that mentor education contributes to a more 
grounded understanding of systematic knowledge for mentors. According to Hobson et al. (2009), mentor education may contribute to developing a stronger professional identity and better education skills, including the ability to enhance reflection. Munthe and Ohnstad (2008) investigated whether mentors considered themselves teacher educators. The results indicated that although some mentors participated in a joint practical community with teacher educators at the university, their professional identities were primarily rooted in their roles as teachers rather than mentors. Research has shown that mentor education can improve not only the quality of teacher education, but also mentors' teaching skills (Giebelhaus and Bowman 2002). In the Norwegian context, studies have proven that mentor education can clarify teachers' roles as mentors and challenge mentors' beliefs about proper mentoring practices (Lejonberg, Elstad, and Christophersen 2015).

Previous research has also indicated that many mentors take pride in their work, especially after witnessing their mentees' success (Beck and Kosnik 2000). Mentoring has also been found to help solidify mentors' professional identity, status, and selfesteem, which likely results from the responsibility involved and their enhanced recognition in the professional community (Bodoczky and Malderez 1997). Some mentors experience a reinvigorated enthusiasm for teaching, reengagement with the profession, and renewed commitment to teaching when mentoring pre-service teachers (Hobson and Malderez 2013; Bodoczky and Malderez 1997).

\section{Theoretical model}

\section{Effort as a dependent variable}

According to Stables et al. (2014), effort is one of the most frequently used terms in everyday conversation in British schools. Willingness to make an effort is considered 
very important for professional performance (Ericsson, Krampe, and Tesch-Römer 1993; Ericsson and Pool 2016; Kahneman 2011). To illustrate with Kahneman's models of systematic thinking, a 'system 1' can quickly create a coherent and believable story based on limited evidence. Such thinking is often characterised by automatic, effortless identification and causal connections between events (Kahneman 2011). In contrast, 'system 2' is slow, deliberate, effortful, and its operations require careful attention. Consequently, improving professional performance requires a deliberate effort to improve (Ericsson and Pool 2016).

Effort seems to be understood differently across cultures (Stables et al. 2014). At the outset of a comprehensive study conducted by Stables et al. (2014), the authors proposed four understandings of effort. After analysing findings from interviews with students, teachers and parents, they devised ten identifiable conceptualisations. Malmberg et al. $(2013,54)$ argued that 'effort can be gauged by time spent on a task and level of exhaustion upon completion'. Based on this premise, we determined that effort defined as time spent — that is, the priority devoted to fulfilling a task — is an important aspect of mentoring effort. Second, we use Stables et al.'s category perseverance. In schools where mentors are subject to unpredictable day-to-day obligations, their willingness to regularly spend time with pre-service teachers is an integral factor in their mentoring effort. Third, we employ effort as reliability of good behaviour, which refers to a mentor's willingness to perform the best they can within certain time limits. This aspect, therefore, concerns the energy mentors invest in performing tasks. Mentors act as models in teaching and relating to students and colleagues (Stables et al. 2014). This is an important aspect of mentoring which is often not made explicit in mentor-mentee relations. Although these three components are not representative of all understandings 
and conceptualisations of effort, they cover the most important aspects operationalised in our questionnaire.

\section{Mentor affective commitment (MC)}

As previously mentioned, teachers and mentors have a variety of complex tasks to accomplish at any given time. The energy and willingness required to spend extra time on integrative efforts can potentially be found in mentors' affective commitment to their job. Therefore, we have placed the variable MC in the exogenous position in our model. In this case, affective commitment is understood as an emotional attachment to, identification with, and involvement in the mentorship role (Lejonberg and Christophersen 2015; Meyer et al. 1991, 2002). Emotions play a vital role in energising certain behaviours, and they may also account for causal mechanisms, which thereby explain these behaviours (Elster 2007). In a similar vein, we propose that positive emotions connected to student relations, progress or outcomes directly support mentors' willingness to spend more time and energy supporting student teachers' development. Like Elster, we agree that social norms, such as the value of hard work, may boost the inclination to make an extra effort. Autonomy — which is often associated with 'enjoyment, sense of purpose and well-being'-also supports mentors' motivation to put forth additional effort (Ryan and Deci 2003, 258; Deci and Ryan 2000). In other words, if mentors identify with a role or activity, they consciously assign personal value to its importance, such as contributing to the development of student teachers.

Mentors' affective commitment to the mentorship of pre-service teachers energises efforts to use, study, and integrate theory in their roles as teacher educators. To illustrate our argument, we specified causal links between mentor integration (MI), affective commitment (MC) and theory use (MTU) to explore the indirect effects on mentor efforts (ME). We propose the following hypothesis (H1): the level of mentors' 
affective commitment to the mentorship role is positively related to the level of mentors' effort.

\section{Mentors' theory use as a mediating variable}

In our structural equation model, mentors' 'use of theory' is used as a mediating variable. This is primarily due to the fact that school mentors' professional development seems highly practice-oriented and based on their own professional experiences and preferences (Clarke, Killeavy, and Moloney 2013; Ulvik and Sunde 2013). Ulvik and Sunde (2013) found that although mentors seem confident in their theoretical understandings, they are less confident in using their knowledge in practice. Such a lack of confidence may also affect mentors' efforts to use theory from campus-based knowledge in their mentoring of pre-service teachers (Hobson et al. 2009). Contrary to a practice-based mentoring style, connecting theory and practice allows much potential for improving pre-service teachers' professional skills (Aspfors and Fransson 2015). A mentor's ability to apply theory, reflection and analysis in their mentoring is crucial to guide students' teaching (Korthagen 2004; Darling-Hammond 2006).

Argyris and Schöns' (1978) theories of practice reveals another perspective on theory use. In mentoring focused on students' thoughts, feelings and actions, theories of practice are concerned with the gulf between espoused theory and theory-in-use. This breach is not inherently problematic, but if it widens, using theory to enlighten practice becomes more difficult. Provided that theory and practice remain connected, the gap creates a dynamic environment for reflection and dialogue. According to Schön (1987), reflection can help mentors understand how teachers develop their professional practices. This is what Schön refers to as reflection-in-action and reflection-on-action (Schön 1987). To summarise, it is commonly argued that theory plays a key role in teachers' professionalism and development, but there seems to be a shortage of 
theoretical reflection and analysis in the mentoring of pre-service teachers. Building on the importance of theory, the following section explores how mentors' use of theory (MTU) may predict mentor efforts (ME) in the model, as well as how it mediates effects from other variables. We propose the following hypothesis $(\mathrm{H} 2)$ : mentors' theory use (MTU) is related to the latent variable mentor effort (ME).

\section{Mentor integration}

Mentor integration is intended to address the 'fragmentation' in teacher education known as 'the theory-practice divide', where theory taught in campus-based settings is seldom reflected in the mentoring of pre-service teachers. It has also been pointed out that actual practice-based and educational institutions must be integrated to provide the most relevant instruction to student teachers (Korthagen, Loughran, and Russell 2006; Flores 2016, 2017; Korthagen 2010; Van Nuland 2011). Mentor integration refers to how mentors educate, how they see themselves and how they are recognised by other educators and institutions. A true integration requires a mutual, open and communicative relationship between mentors and teacher education institutions, where mentors spend time and effort to be integrated. Our focus on mentor integration is also closely associated with the emerging focus on professionalism in teacher education programmes (Darling-Hammond 2006). In both school- and university-based programmes, instructors should have professionalised roles in the education of student teachers. Maintaining professional consistency is important for university teachers and school mentors to share a relative consensus over what constitutes proper performance, professionalism and practice (Darling-Hammond 2006; Smith 2016). Mentor integration also entails school-based teachers seeing themselves not just as teachers, but also as teacher educators. Based on the effort required to integrate, we explore how mentor integration may predict mentor effort. We propose the following hypothesis $(\mathrm{H} 3)$ : the 
level of mentor integration is positively related to the level of mentor effort.

As mentioned, scholars have shown that mentor education is vital for improving the mentoring of pre-service teachers (Hobson et al. 2009; Ulvik and Sunde 2013). Based on this evidence, we predict that mentor education (V2) will predict the level of effort that mentors devote to their jobs (H4). Mentor experience (V88) is another relevant factor that may be associated with mentor effort (ME). More experience may lead to routine-based mentoring, which requires less effort. We propose that greater mentor experience may lead to less effort being invested in mentoring pre-service teachers (H5).

\section{TABLE 1 HERE}

\section{Context}

The five-year teacher education programmes in Norway require pre-service teachers to have 60-100 days of school-mentored practice, and they also require school mentors to have at least 15 credits in mentoring (Ministry of Education and Research, 2013, 2016). The five-year teacher education programmes require pre-service teachers to have 60 100 days of school-mentored practice, and they also require school mentors to have at least 15 credits in mentoring. Teacher education programmes in Norway vary in structure. However, all pre-service teachers in teacher education for primary (students aged 6-12), lower secondary (aged 13-15) and upper secondary schools (16-18) attend 60-100 days of field placement. In some programmes, practicum consists of two relatively long periods carried out in one year. In other programmes, the days are divided among several periods during a five-year master study. Student assessments are a shared responsibility between school-based mentors and the teacher education institution. The students are usually mentored by several mentors during their 
practicum. The sample was drawn from three teacher education institutions: two universities training lower and upper secondary school teachers and one university college training primary education teachers.

\section{Sample}

Due to overuse of evaluative questionnaires in schools it is difficult to do survey research and get a good response-rate. Our strategy was therefore to obtain a largest possible sample and a greatest possible variety using school practice coordinators and a tutor meeting to collect paper questionnaires and scanned the responses. The sample may not be representative for the population of mentors but still indicative of what might be revealed. Below is a description of the sample using distribution of gender and number of years in tutoring.

\section{TABLE 2 HERE}

The hypotheses were tested using questionnaire data from 258 mentors out a total sample of 295 mentors. 37 mentors had missing on at least one variable in the model. For one mentor education program, the data were collected by administrators at a lecture for mentors, which resulted in close to a $100 \%$ response rate from the school mentors who attended. For the other two programmes, the same questionnaires were distributed to contact teachers in local practice schools, and they were then distributed to and collected from school mentors. The mentors who attended mentor education courses participated in programmes designed within a national framework, which provides guidelines and establishes content, methods, objectives, learning goals and admission criteria for mentor training courses. Gathering data from schools and mentor education programmes resulted in a mixed cohort of mentor respondents. 


\section{Measurement}

The questionnaire was designed based on new measurement instruments, as well as instruments previously used in other studies. The MC instrument was adopted from previous works (Lejonberg and Christophersen 2015; Lejonberg, Elstad, and Christophersen 2015), while other instruments were developed from the work of Haladyna and Rodriguez (2013). In the survey, mentors responded to items on a sevenpoint Likert like scale, ranging from 'completely agree' to 'completely disagree', where option four represented a neutral midpoint.

\section{Mentor effort as a latent variable}

Referring to the theory section, we constructed items that designate completing extra work and maintaining a high quality of work performance as indicators of mentor effort. The operationalisation is based on Stables et al. (2014), Cronbach's alpha was $\alpha_{c}=.74$

- I prioritise the mentoring work, even though I am busy doing other things (38)

- I am very keen to make a significant contribution as a mentor (40)

- I often add extra effort to my job as a mentor (41)

\section{Affective commitment to the mentoring role}

The MC measurement was adopted from Lejonberg and Christophersen (2015), and the results reflect different effects. The internal consistency, Cronbach's alpha, was .86, which was satisfactory. The items included to measure this variable were:

- I am proud of being a mentor (20)

- I am enthusiastic about the mentorship role (21)

- I am pleased to be able to sign up as a mentor (22) 


\section{Mentor theory use as a mediating variable}

Previous literature on mentor theory use emphasises that a mentor's theoretical and analytical skills, as well as acuity for reflection, are key elements for developing mentor skills (Aspfors and Fransson 2015). The Cronbach's alpha was .82.

- Do you refer to literature as a basis for conversations with the student? (64)

- Do you encourage students to reflect upon practice considering the literature being used? (65)

- Do you inform your mentoring practice with theory and literature on teaching and learning? (66)

\section{Mentor integration}

Based on the research review of teacher professionalism, the integration of theory and practice (Darling-Hammond and Lieberman 2012; Korthagen 2010; Hobson et al. 2009) and the relatedness and regulation of identities (Ryan and Deci 2003), the mentor integration variables highlighted two aspects of mentor involvement in teacher education: the way mentors perceived themselves as teacher educators (81-82) and the way mentors viewed themselves as integrated into campus education. The Cronbach's alpha was .78.

- I see myself as a teacher educator (81)

- I find that teachers from the training institution appreciate the job we are doing as an important part of teacher education (84)

- Mentors are teacher educators on an equal basis with those who work on campus $(85)$

\section{Analytical procedures}

We used structural equation modelling (SEM) in IBM Amos and present complete 
effect tables. We began by exploring how mentors' affective commitment (MC), perceived integration (MI), use of theory (MTU), education (V2), and experience (V88) are related to mentor effort. The model is specified with mentor affective commitment (MC) as the independent variable and mentor effort (ME) as the dependent variable. Mentor integration (MI) and mentor theory use (MTU) are specified as the first and second mediating variables. Mentor education (V2) and years of mentor experience (V88) are specified as control variables.

In the following procedures, all distributions were checked for skewness and kurtosis, and all were well below the threshold 2. Model fit was assessed using $\chi^{2}$ the associated p-value (p-kji), the root mean square error of approximation (RMSEA), the Tucker-Lewis index (TLI), the goodness-of-fit index (GFI) and the comparative fit index (CFI). p-kji >.05, RMSEA $<.05$ and TLI, GFI and CFI $>.95$ indicated good fit, while RMSEA $<.08$ and TLI, GFI and CFI >.90 indicated acceptable fits (Byrne 2010; Kline 2005). The p-value of .047 is below but close to .05 , indicating that the fit is not entirely satisfactory. The RMSEA value of .033 indicates a good fit. A TLI of .90 is indicating acceptable fit. The GFI value of .95 indicates good fit, and the CFI value of .92 indicates good/acceptable fit. The conclusion is that the model has satisfactory fit.

\section{Results}

We begin our analysis by commenting upon the bivariate correlations with the dependent variable ME.

\section{TABLE 3 HERE}

In the table, V2 (mentor education) and V88 (mentor experience) are observed variables. The bivariate correlations between the latent variables are uneven. Starting 
with the strongest, $\mathrm{MC}$ correlates $\mathrm{r}=.72$ with $\mathrm{ME}$, which reflects very strong associations, but we still think the discriminant validity between the concepts is sufficiently good. The second strongest correlation of $\mathrm{r}=.56$ is MI, which is also very high, and the third strongest is MTU r=.46. Despite their minor differences, all three variables seem to be strongly associated with mentor effort. Mentor education correlated moderately, but significantly, with mentor effort. Experience, on the other hand, correlates insignificantly with ME, and the correlation appears to be negative. The numbers in rows two and six will be elaborated on. In the model below, we provide the results from our structural model between latent and observed variables.

\section{FIGURE 1 HERE}

Starting with the latent variables, mentor commitment (MC) is clearly the most important predictor of mentor effort (ME). A coefficient of .57 indicates that affective commitment has a strong predictive value. MC also is strongly associated with MI and more moderately associated with greater use of theory (MTU) among mentors in their practice. Both MI and MTU also exert some effects on ME. These results support our assumption that positive emotions related to teacher support and development energises mentors to perform better or simply spend more time with students. This energy could also be used to enhance theory use in mentoring practice. There is only a small spurious effect, and MC is clearly the most important contributor to mentor effort, controlled for other variables in the model. Hypothesis 1 is supported.

Despite a strong bivariate correlation, MI has almost no direct contribution to ME controlling for other variables in the model. However, MI has a medium to strong contribution to MTU, where the latter has a small direct effect on ME. With MTU as a mediating variable, MI has a small indirect effect on ME, controlled for the other 
variables in the model. However, MI has a large spurious effect, which is non-causal (see Figure 1). Despite this strong bivariate correlation, MI's contribution to ME is rather small when controlled for other variables. Still, MI's contribution to MTU is quite substantial. Hypothesis 2 is not supported.

MTU has only a small direct contribution to ME, but the variable seems to attract effects from MC and MI, in particular. The mediation of indirect effects underlines the significance and potential for theory use and its contribution to perceived mentor effort. We therefore emphasise theory use's importance in mentor practice. Hypothesis 3 is moderately supported.

Mentor education (V2), seems to have a small contribution to mentor effort. However, it has an important medium indirect effect on $\mathrm{MC}$ and a somewhat smaller indirect effect on MTU. Both effects seem related to completing a mentor education, which involves reading, practicing and attending lectures. Hypothesis 4 is moderately supported.

Having previous mentor experience seems to have an insignificant effect on mentors' efforts in supporting pre-service teachers. Also, there are no indirect contributions in the model. We find the lack of contributions (direct and indirect) from mentor experience quite noteworthy. Hypothesis 5 is not supported.

\section{Limitations of study}

Strictly speaking, the findings in this study are only valid for the present sample. However, the results may be extended to mentors affiliated with the educational programmes in question. There are also weaknesses in the concept measurement process, which uses only three items to obtain a good fit. Additionally, a limited number of concepts were examined. These shortcomings may be addressed in future research. Some path coefficients were small, and thus should be interpreted with caution. 
Nevertheless, the basic theoretical model was based on such a strong research foundation that it is highly unlikely the statistical associations highlighted in this study are a result of coincidence or spurious connections.

\section{Discussion}

Education quality most often depends on the effort teachers are able and willing to put into their work. Most teachers struggle to find the time for their various obligations, while policy makers and education leaders demand the best from overworked educators. This study illuminated a clear connection between mentors' affective commitment and mentor performance. These results may also have implications on the use of theory in reflective practice, mentors' time and energy investment, and integration in teacher education programmes. High commitment, therefore, seems attractive to all parties involved in teacher mentoring. Theoretically, sources of affective commitment may come from teacher mentors' successful experiences and positive feedback from students. Such positive experiences may also boost teacher mentors' efficacy (Bandura 1997). Other sources of affective work commitment are support and appreciation from school leaders, well adapted work plans with sufficient space for tutoring and economic rewards.

Mentor autonomy can also potentially support positive professional development. If these associations reflect causal processes, teacher mentors should cautiously communicate what prevents them from having energising experiences, while school leaders and policymakers should pay close attention to these concerns. Considering the potential affective commitment seems to have for mentors' professional effort, the specific sources of such energising attitudes should be investigated in more detail. This finding could be seen in tandem with qualitative studies in future research. 
Affective commitment may also be related to the use of theory and willingness to integrate. Based on these findings, it may be argued that support for mentor commitment might be an adequate response to the fragmentation challenge in teacher education, particularly when integrative processes and theory use is facilitated and encouraged. We acknowledge possible mutual causal relationships between MI, MTU and ME. Mentors' perceived integration in teacher education does not appear to inspire mentors to make an extra effort and contribute to pre-service teachers' professionalisation. However, playing an integral role in teacher education might contribute to the use of theory, which is in turn associated with mentor effort.

Mentor education has an impact on mentors' affective commitment to their jobs. Schön's (1987) perspectives on the reflective practitioner shed light on how teachers develop their professional practices through reflection. If teacher education programmes consider this approach to professional learning, it could foster the professionalisation of the mentorship role. Studies on mentor education in Norway indicate that professionalisation contributes to role clarity and affective commitment (Lejonberg, Elstad, and Christophersen 2015; Lejonberg and Tiplic 2016). Constraints such as lack of time, resources, motivation and effort must be addressed to improve mentor performance (Ericsson and Pool 2016). Because mentor education contributes to mentors' affective commitment to their jobs, this could also affect the effort they put into their work. Mentors' theory use also seems to be an important professional aspect of teaching, which contributes to mentor effort.

This attempt to theorise central aspects of mentors' effort in teacher education could contribute to a theoretical model for examining effort and the institutional, contextual, and personal aspects that influence mentor engagement. Our model indicates that mentor commitment is strongly related to mentor effort. Interpreting this through 
the lens of Ryan and Deci's (2003) work on relations, relatedness and the need for autonomy, mentors' feeling of commitment to their work depends upon how they identify with the activities they perform as mentors. The stronger the mentor's sense of professional and personal identity, the more effort they will put into the job. Then, they will increase effort by finding time and using the time properly to fulfil tasks. The mentor will have perseverance in both teaching and mentoring. Both time use and perseverance are categories developed by Stables et al. (2014) in attempting to theorise effort as a concept. Our findings show that the last category of effort, reliability of good behaviour, is also related to mentor commitment.

It is quite noteworthy that mentors' experience has such a minor impact on mentor effort. The small direct effect, which is negative, suggests that more experienced mentors may invest less effort supporting pre-service teachers. We assume this occurs when experience reinforces routine. Teaching then requires less effort to gain the same results for students. Therefore, experience — understood as years of practice — does not necessarily lead to mentors exerting more effort. Rather, experience may have other positive effects, such as undertaking mentor education and developing better qualitative support skills, but this is not explored in the current study.

\section{Recommendations}

To summarise, affective commitment is a steady predictor of mentors' efforts. Determining how to support affective commitment may be difficult, but we believe mastering the art of mentor education can contribute to higher levels of mentor effort and commitment. Our principal suggestion, therefore, is that educational leaders and authorities offer more resources and various incentives to support mentors' commitment and thereby enhance their inclination to make an extra effort. 
Although mentor integration does not contribute much to mentor effort when controlled for other variables, it remains to be seen how improved integration might contribute to mentor effort. Despite mentor education's small direct contribution to mentor effort, it is currently unclear if other educational programmes of a different design might yield a larger contribution. In particular, we encourage studying programmes which provide effective guidance and support for pre-service teachers in their personal and professional development.

In conclusion, mentors' theory use plays an important mediating role in enhancing teachers' efforts, as well as their professionalism. Efforts to stimulate reflection on the relationship between theory and practice should therefore become common in schools. Mentor education also stimulates theory-practice reflection, which is particularly relevant to the educational programmes in question. We therefore recommend to support that mentors perform as reflective models for preservice teachers. 


\section{References}

Aspfors, Jessica, and Göran Fransson. 2015. "Research on Mentor Education for Mentors of Newly Qualified Teachers: A Qualitative Meta-Synthesis.” Teaching and Teacher Education 48: 75-86. doi:10.1016/j.tate.2015.02.004.

Beck, Clive, and Clare Kosnik. 2000. "Associate Teachers in Pre-Service Education: Clarifying and Enhancing Their Role." Journal of Education for Teaching 26 (3): 207-24. doi:10.1080/713676888.

Bodoczky, Caroline, and Angi Malderez. 1997. "The INSET Impact of a Mentoring Course.” In In-Service Teacher Development: International Perspectives, edited by D. Hayes. Hemel Hempstead: Prentice Hall.

Bullough Jr., Robert V. 2005. "Being and Becoming a Mentor: School-Based Teacher Educators and Teacher Educator Identity." Teaching and Teacher Education 21 (2): 143-55. doi:10.1016/j.tate.2004.12.002.

Byrne, Barbara M. 2010. Structural Equation Modeling with AMOS: Basic Concepts, Applications, and Programming. New York: Routledge.

Clarke, Anthony, Valerie Triggs, and Wendy Nielsen. 2014. "Cooperating Teacher Participation in Teacher Education: A Review of the Literature." Review of Educational Research 84 (2): 163-202. doi:10.3102/0034654313499618.

Darling-Hammond, Linda. 2006. "Constructing 21st-Century Teacher Education." Journal of Teacher Education 57 (3): 300-314. doi:10.1177/0022487105285962.

Darling-Hammond, Linda, and Ann Lieberman. 2012. Teacher Education around the World: Changing Policies and Practices. New York: Routledge.

https://eric.ed.gov/?id=ED530535.

Deci, Edward L., and Richard M. Ryan. 2000. "The 'What' and 'Why' of Goal Pursuits: Human Needs and the Self-Determination of Behavior." Psychological Inquiry 11 (4): 227-68. doi:10.1207/S15327965PLI1 104.

Ericsson, K. Anders, Ralf T. Krampe, and Clemens Tesch-Römer. 1993. "The Role of Deliberate Practice in the Acquisition of Expert Performance." Psychological Review 100 (3): 363-406. doi:10.1037/0033-295X.100.3.363.

Ericsson, K. Anders, and Robert Pool. 2016. Peak: Secrets from the New Science of Expertise. Boston: Houghton Mifflin Harcourt. Boston: Houghton Mifflin Harcourt.

Evans, Linda, and Ian Abbott. 1997. "Developing as Mentors in School-Based Teacher Training." Teacher Development 1 (1): 135-48. doi:10.1080/13664539700200010. 
Feiman-Nemser, Sharon. 2001. "From Preparation to Practice: Designing a Continuum to Strengthen and Sustain Teaching." Teachers College Record 103 (6): 1013-55. http://www.geocities.ws/cne_magisterio/4/curricfomdocente.pdf.

Giebelhaus, Carmen R., and Connie L. Bowman. 2002. "Teaching Mentors: Is It Worth the Effort?" The Journal of Educational Research 95 (4): 246-54. doi:10.1080/00220670209596597.

Goodfellow, Joy. 2000. "Knowing from the inside: Reflective Conversations with and through the Narratives of One Cooperating Teacher." Reflective Practice 1 (1): 2542. http://www.tandfonline.com/doi/pdf/10.1080/713693136? needAccess=true. Goodlad, John. 1990. Teachers for Our Nation's Schools. San Francisco, CA: JosseyBass Publishers.

Haladyna, Thomas M., and Michael C. Rodriguez. 2013. Developing and Validating Test Items. New York: Routledge.

Hascher, Tina, Yves Cocard, and Peter Moser. 2004. "Forget about Theory-Practice Is All? Student Teachers' Learning in Practicum.” Teachers and Teaching 10 (6): 623-37. doi:10.1080/1354060042000304800.

Hobson, Andrew J., Patricia Ashby, Angi Malderez, and Peter D. Tomlinson. 2009. “Mentoring Beginning Teachers: What We Know and What We Don't." Teaching and Teacher Education 25 (1): 207-16. doi:10.1016/j.tate.2008.09.001.

Hobson, Andrew J., Angi Malderez, Louise Tracey, Marina Giannakaki, Godfrey Pell, and Peter D. Tomlinson. 2008. “Student Teachers' Experiences of Initial Teacher Preparation in England: Core Themes and Variation." Research Papers in Education 23 (4): 407-33. doi:10.1080/02671520701809825.

Hobson, Andrew J., and Angi Malderez. 2013. "Judgementoring and Other Threats to Realizing the Potential of School-based Mentoring in Teacher Education." International Journal of Mentoring and Coaching in Education 2 (2): 89-108. doi:10.1108/IJMCE-03-2013-0019.

Kahneman, Daniel. 2011. Thinking Fast and Slow. New York: Farrar, Straus and Giroux.

Kline, Rex B. 2005. Principles and Practice of Structural Equation Modeling. New York: Guilford.

Knowles, Gary J., and Ardra L. Cole. 1996. "Developing Practice through Field Experiences." In The Teacher Educator's Handbook: Building a Knowledge Base for the Preparation of Teachers, edited by F.B. Murray, 648-88. San Francisco, 
CA: Jossey-Bass Publishers.

Kochan, Frances, Linda Searby, Manju P. George, and Jon Mitchell Edge. 2015.

"Cultural Influences in Mentoring Endeavors: Applying the Cultural Framework

Analysis Process." International Journal of Mentoring and Coaching in Education 4 (2): 86-106. doi:10.1108/IJMCE-03-2015-0010.

Korthagen, Fred. 2004. "In Search of the Essence of a Good Teacher: Towards a More

Holistic Approach in Teacher Education." Teaching and Teacher Education. doi:10.1016/j.tate.2003.10.002.

- 2010. "How Teacher Education Can Make a Difference." Journal of Education for Teaching 36 (4): 407-23. doi:10.1080/02607476.2010.513854.

Korthagen, Fred, and Theo Wubbels. 1995. "Characteristics of Reflective Practitioners:

Towards an Operationalization of the Concept of Reflection.” Teachers and

Teaching 1 (1): 51-72. doi:10.1080/1354060950010105.

Lee, John Chi-kin, and Shengyao Feng. 2007. "Mentoring Support and the Professional

Development of Beginning Teachers: A Chinese Perspective." Mentoring \&

Tutoring: Partnership in Learning 15 (3): 243-62.

doi:10.1080/13611260701201760.

Lejonberg, Eli, and Knut-Andreas Christophersen. 2015. "School-based mentors' affective commitment to the mentor role: Role clarity, self-efficacy, mentor education and mentor experience as antecedents." International Journal of Evidence Based Coaching \& Mentoring, 13 (2), 45-63. Retrieved from http://escweb.lib.cbs.dk/login?url=http://search.ebscohost.com/login.aspx?direct=true $\% 7 B \&$ \%7Ddb=bth\%7B\&\%7DAN=108806880\%7B\&\%7Dlogin.asp\%7B\&\%7Dsite=ehos t-live\%7B\&\%7Dscope $=$ site\%5Cnhttp://esc-

web.lib.cbs.dk/login?url=http://search.ebscohost.com/login.aspx?dir

Lejonberg, Eli, Eyvind Elstad, and Knut-Andreas Christophersen. 2015. "Mentor education: Challenging mentors' beliefs about mentoring." International Journal of Mentoring and Coaching in Education, 4 (2), 142-158. https://doi.org/10.1108/IJMCE-10-2014-0034

Lejonberg, Eli, and Dijana Tiplic. 2016. "Clear mentoring: Contributing to mentees? Professional self-confidence and intention to stay in their job." Mentoring \& Tutoring: Partnership in Learning, 24 (4), 290-305. https://doi.org/10.1080/13611267.2016.1252110 
Malmberg, Lars-Erik, Theodore Walls, Andrew J. Martin, Todd D. Little, and Wee H. T. Lim. 2013. "Primary School Students' Learning Experiences of, and SelfBeliefs about Competence, Effort, and Difficulty: Random Effects Models.” Learning and Individual Differences 28: 54-65.

Meyer, John P., D. Ramona Bobocel, and Nancy J. Allen. 1991. "Development of Organizational Commitment during the First Year of Employment: A Longitudinal Study of Pre- and Post-Entry Influences." Journal of Management 17 (4): 717-33. doi:10.1177/014920639101700406.

Meyer, John P., David J. Stanley, Lynne Herscovitch, and Laryssa Topolnytsky. 2002.

"Affective, Continuance, and Normative Commitment to the Organization: A Meta-Analysis of Antecedents, Correlates, and Consequences." Journal of Vocational Behavior 61 (1): 20-52. doi:10.1006/jvbe.2001.1842.

Ministry of Education and Research. 2013. Regulations Relating to the Framework Plan for Lower and Upper Secondary Teacher Education for Years 8-13. Oslo: Ministry of Education and Research. https://lovdata.no/dokument/SF/forskrift/2013-03-18-288?q=Forskrift om rammeplan $\mathrm{f}$.

- 2016. Regulations Relating to the Framework Plan for Primary and Lower Secondary Teacher Education for Years 5-10. Oslo.

https://www.regjeringen.no/contentassets/c454dbe313c1438b9a965e84cec47364/f orskrift-om-rammeplan-for-grunnskolelarerutdanning-for-trinn-5-10---engelskoversettelse.pdf.

Munthe, Elaine, and Frøydis Oma Ohnstad. 2008. "Ensomme Svaler? En Studie Av Praksisskolelæreres Rapportering Om Identitet, Kollektivitet Og Gjennomføring Av Praksisopplæringsperioder." Norsk Pedagogisk Tidsskrift, 92 (6): 471-482.

Orland-Barak, Lily. 2014. "Mediation in Mentoring: A Synthesis of Studies in Teaching and Teacher Education.” Teaching and Teacher Education 44: 180-88. doi:10.1016/j.tate.2014.07.011.

—. 2016. "Mentoring." In International Handbook of Teacher Education: Volume 2, edited by John Loughran and Mary Lynn Hamilton, 105-41. Singapore: Springer Science+Business Media. doi:DOI 10.1007/978-981-10-0369-1_4. Robinson, Irene, and John Robinson. 1999. "Learning to Live with Inconsistency in Student Entitlement and Partnership Provision." Mentoring and Tutoring: Partnership in Learning 7: 223-39. 
Ryan, Richard M., and Edward L. Deci. 2003. "On Assimilating Identities to the Self: A Self-Determination Theory Perspective on Internalization and Integrity within Cultures.” In Handbook on Self \& Identity, edited by Mark R. Leary and June P. Tangney, 253-74. New York: The Guilford Press.

Schön, Donald A. 1987. Educating the Reflective Practitioner: Toward a New Design for Teaching and Learning in the Professions. San Francisco, CA: Jossey-Bass Publishers. doi:10.1182/blood-2010-02-266338.

Simpson, Tracy, Wendy Hastings, and Bob Hill. 2007. "'I Knew That She Was Watching Me': The Professional Benefits of Mentoring." Teachers and Teaching 13 (5): 481-98. doi:10.1080/13540600701561695.

Skaalvik, Einar M., and Sidsel Skaalvik. 2018. "Job Demands and Job Resources as Predictors of Teacher Motivation and Well-Being." Social Psychology of Education (August 2018): 1-25. doi:10.1007/s11218-018-9464-8.

Smith, Kari. 2016. "Partnerships in Teacher Education - Going beyond the Rhetoric, with Reference to the Norwegian Context." Center for Educational Policy Studies Journal 6 (3): 17-36. http://files.eric.ed.gov/fulltext/EJ1128734.pdf.

Stables, Andrew, Kyoko Murakami, Shona Mcintosh, and Susan Martin. 2014. "Conceptions of Effort among Students, Teachers and Parents within an English Secondary School." Research Papers in Education 29 (5): 626-648. doi:10.1080/02671522.2013.878376.

Thornton, Kate. 2014. "Mentors as Educational Leaders and Change Agents." International Journal of Mentoring and Coaching in Education 3 (1): 18-31. doi:10.1108/IJMCE-07-2013-0038.

Ulvik, Marit, and Eva Sunde. 2013. "The Impact of Mentor Education: Does Mentor Education Matter?” Professional Development in Education 39 (5): 754-70. doi:10.1080/19415257.2012.754783. 
Figure 1

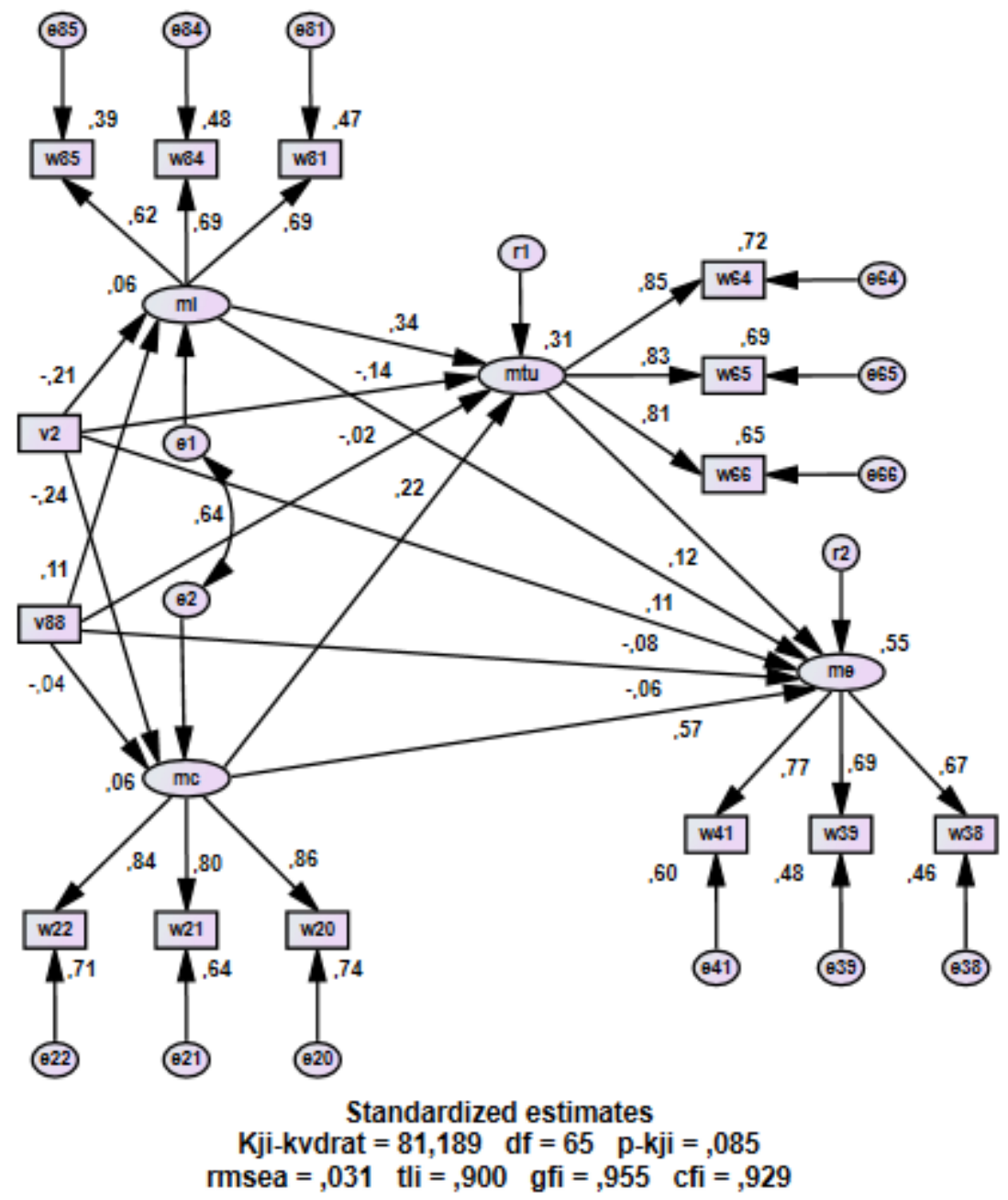

Figure 1. Empirical path-model $(\mathrm{n}=265 \& \mathrm{ML})$

Mentor effort (ME) is a dependent variable. Mentor use of theory (MTU) is a mediating variable while mentor integration (MI), mentor commitment (MC), mentor education (V2) and years of mentor experience (V88) are independent variables. Numbers between latent variables are standardised regression coefficients. The overall fit of this model is very good with RMSEA $=.031$. The good TLI indicates that the model is not too complex. The CFI and GFI is satisfactory and well above .90 . 


\section{Tables}

Table 1. Hypotheses in this study of mentor effort

\begin{tabular}{|l|l|}
\hline H1 & $\begin{array}{l}\text { The level of affective commitment to the mentor role is positively related } \\
\text { to the level of mentor effort. }\end{array}$ \\
\hline H2 & $\begin{array}{l}\text { Mentors' use of theory is related to the latent variable mentor effort (ME). } \\
\text { effort. }\end{array}$ \\
\hline H4 & $\begin{array}{l}\text { Mentor education will predict the level of effort that mentors put into their } \\
\text { jobs. }\end{array}$ \\
\hline H5 & Mentor experience may lead to less invested effort in mentoring. \\
\hline
\end{tabular}

Table 2. Sample $\mathrm{N}=295$ from three institutions/education programmes (OU and TU and $\mathrm{TP})$. The following table displays the distribution of gender and years of practice in the sample.

\begin{tabular}{l|c|c}
\hline \multicolumn{1}{c|}{ OU secondary } & TU secondary & TP primary \\
\hline Variables & 155 & 74 \\
\hline Gender & Number & Percent \\
Females & & \\
Males & 173 & 67.1 \\
\hline Total & 85 & 32.9 \\
\hline Years of & 258 & 100.0 \\
tutoring & & \\
experience & & \\
$1-5$ years & 156 & 60.5 \\
$6-10$ years & 63 & 24.4 \\
$11-15$ years & 25 & 9.7 \\
$16-32$ years & 14 & 5.4 \\
\hline Total & 258 & 100.0 \\
\hline Mentor & & \\
education & & 35.7 \\
Yes & 92 & 64.3 \\
No & 166 & \\
\hline
\end{tabular}




\begin{tabular}{l|c|c}
\hline Total & 258 & 100.0 \\
\hline
\end{tabular}

Table 3. Bivariate correlations with the dependent variable ME

\begin{tabular}{llllll}
\hline ME & V2 & V88 & MI & MC & MTU \\
\hline 1: Bivariate & -.28 & -.07 & .56 & .72 & .46 \\
2: Total & -.28 & -.07 & .15 & .60 & .12 \\
3: Direct & -.08 & -.06 & .11 & .57 & .12 \\
4: Indirect & -.20 & -.01 & .04 & .03 & .00 \\
5: Spurious & .00 & .00 & .41 & .12 & .34 \\
\hline 6: $\mathbf{R}^{2}$-me $=.55$ & & & .06 & .06 & .31 \\
\hline
\end{tabular}

Table 3. First row: Bivariate correlations between latent and observed (V2-V88) variables, independent variables, and the dependent variable in our final path model. Rows two through five display the total and decomposed effects of independent variables on the dependent variable. The last row shows variables contributing to explained variance. Numbers are Pearson's r. V2 represents mentor education, and V88 represents years of mentor experience. 